laryngologists. I think it is a serious fault to consider training doctors who would only be able to work in an urban area with immediate access to an ENT department. Doctors working anywhere else in the country or the world must know something of laryngeal appearances in the mirror. To leave out this aspect of ENT reduces the value of this book very considerably.

Should another edition include indirect laryngoscopy and its findings in disease, this book would become most useful to students and, indeed, to ENT registrars as well.

\section{Disorders of the Blood. A Textbook of Clinical Haematology}

By R. B. Thompson. Pp. 851, illustrated. Churchill

Livingstone, Edinburgh, London, New York, 1977. $£ 30.00$

Dr R. B. Thompson has undertaken the enormous task of producing a major text in haematology single-handed. The outcome is this beautifully produced book by Churchill

Livingstone, Edinburgh, London, New York, 1977. +30.00 . admirably balanced in a manner that is only possible with limited authorship (or perhaps paranoid editors).

In length (851 large pages) it stands between the shorter texts and longer books such as that edited by Williams, Beutler, Erslev and Rundles (1755 pages). Each chapter sets out the background, clinical presentation and treatment with clarity and with emphasis on the clinical rather than the backroom aspects of the disorders. Each chapter is accompanied by a very full list of references. Everyone with an interest in haematology will want to possess a copy of this book. It can be recommended to those sitting advanced examinations in haematology such as the final examination of the Royal College of Pathologists in the U.K. Perhaps the next edition will see an expansion of the section on blood coagulation and its disorders and a shrinkage of the mean red cell corpuscular volume since the range 76 to $96 \mathrm{fl}$. has an antique pre-Coulterian ring about it.

\section{Epidemiology of Head Injuries in England and Wales. With Particular Application to Rehabilitation}

By J. H. Field. Pp. $109+$ viii, illustrated, soft cover. Crown Copyright HMSO, London. Copies from Department of Health and Social Security: Research Division.

This study by Dr Field of the Research Division of the DHSS was undertaken at the instigation of the Research Liaison Group for the Socially Handicapped. Originally designed as a study of rehabilitation, it was extended back in time to the outcome of injury in terms of mortality and morbidity, the cause of the injury and the social and other factors affecting the incidence. It does not include original work by the author, but is rather a review of the past and current research, with the aim of making recommendations. These are comprehensive, but are mainly concerned with the major deficiencies in basic knowledge still present and the areas for further longterm research. Yet, observations such as 'in the Midlands and the North, above average mortality is combined with below average hospital admission and the reverse applies in London' suggest more immediate action and, at least, an urgent review of the in-patient facilities in the North and Midlands.

Probably because of the original commission, very little is said about prevention. Road traffic accidents are the commonest cause of head injury. It is sometimes difficult from the Report to interpret the figures as the number of deaths in each age group are given, but do not include age-related mortality rates. However, the highest mortality occurs among the car occupants in the age range 15-45 years, among motor cycle riders 15-25 years and among pedestrians 0-25 years and 45 years and over. Overall, the lowest mortality for road traffic accident head injuries is among the age groups $0-5,25-45$ and over 75 years. Thus, young adults aged 15-25 years, whether on a motor cycle or in a car are the most vulnerable. Unfortunately, the report says little about car design in the prevention of head injury, but the figures suggest that there is as much need to consider the pedestrian as there is the car occupants.

This book gives a good review of the studies that have been carried out on head injuries and rehabilitation following them. It also provides many interesting suggestions for further research.

\section{General Surgical Operations}

Edited by R. M. KIRK. Pp. 412, illustrated. Churchill

Livingstone, Edinburgh, London, New York, 1978.£16.00. The best way to learn operative surgery is to watch, or better still to assist, a master surgeon, and then to carry out the same procedure under his supervision. This ideal but slow process would hardly enable a surgeon in training to gain experience of the broad spectrum of operations he might be called upon to describe in the operative surgery examination which is perhaps the most terrifying part of the FRCS. The reviewer speaks here with feeling since it was in this section that he failed ignominiously at his first attempt at this pinnacle 28 years ago!

Since the candidate cannot possibly have personal experience or even see every standard operation, there is undoubtedly a need for textbooks which provide a clear description of the standard procedures which the general surgeon in training needs to know. Mr Kirk has skilfully managed to cover these in a single volume of reasonable size. He has co-opted 18 expert contributors - many of them his present or former colleagues at the Royal Free Hospital - and includes those operations of gynaecology, obstetrics, paediatrics, dentistry, eyes and ENT which a general surgeon mighP be called upon to perform. There is also a useful chapter or anaesthesia and related techniques. The descriptions are clear, authoritative and supplemented by numerous excellen line diagrams by that skilled medical artist, Mr Frank Price This is a book which will undoubtedly prove valuable to surgical candidates for higher degrees and has an assurec success.

\section{An Introduction to Cell Population Kinetics}

By W. A. Aherne, R. S. Camplejohn and N. A. Wright? Pp. 88, illustrated, soft back. Edward Arnold, London, 1977. $£ 2.95$.

The aim of this book is to introduce the principles and practice of cell population kinetics to scientists who are unfamiliar with this relatively new discipline.

The events of the cell cycle and factors controlling the size of cell populations are discussed and several methods of analysing proliferating cell populations (metaphase blockade, radio isotope labelling and microdensitometry) are evaluated. The classification of cells and their subdivision into compartments is presented diagrammatically and parameters for measuring dividing cells and assessing cell loss and cell gain are clearly stated and presented in mathematical form together with worked examples.

The terminology of cytokinetics may not be familiar to newcomers to the subject and a glossary of cytokinetic terms is included in the book. While this is most helpful, it could with advantage be expanded to include definitions of indices such as specific growth rate, pulse labelling index, etc. so that the reader does not have to search the text repeatedly to remind himself of their meanings. It is a pity that the authors do not include a chapter on the application of cell kinetics to clinical medicine, which is an aspect of particular interest to medically qualified readers.

This introductory book prepares the way for further study of dividing cell populations. Scientists who are newly involved in research in this field will find it provides a rational basis for their work and histopathologists whose work involves analysis of fixed and frozen sections will gain an insight into the dynamics of living tissue. 